\title{
Methods for identifying lipoxygenase producing microorganisms on agar plates
}

\author{
Antti Nyyssölä ${ }^{1 \dagger}$, Ruud Heshof ${ }^{2 \dagger}$, Thomas Haarmann ${ }^{3}$, Jasmin Eidner ${ }^{3}$, Ann Westerholm-Parvinen ${ }^{1}$, Kim Langfelder ${ }^{3}$, \\ Kristiina Kruus ${ }^{1}$, Leo de Graaff ${ }^{*}$ and Johanna Buchert ${ }^{1}$
}

\begin{abstract}
Plate assays for lipoxygenase producing microorganisms on agar plates have been developed. Both potassium iodide-starch and indamine dye formation methods were effective for detecting soybean lipoxygenase activity on agar plates. A positive result was also achieved using the $\beta$-carotene bleaching method, but the sensitivity of this method was lower than the other two methods. The potassium iodide-starch and indamine dye formation methods were also applied for detecting lipoxygenase production by Trichoderma reesei and Pichia pastoris transformants expressing the lipoxygenase gene of the fungus Gaeumannomyces graminis. In both cases lipoxygenase production in the transformants could be identified. For detection of the G. graminis lipoxygenase produced by Aspergillus nidulans the potassium iodide-starch method was successful. When Escherichia coli was grown on agar and soybean lipoxygenase was applied on the culture lipoxygenase activity could clearly be detected by the indamine dye formation method. This suggests that the method has potential for screening of metagenomic libraries in E. coli for lipoxygenase activity.
\end{abstract}

\section{Introduction}

Lipoxygenases (EC 1.13.11.12, EC 1.13.11.34 and EC 1.13.11.33) are non-heme, iron or manganese containing enzymes which catalyze the oxidation of unsaturated fatty acids containing a 1-cis,4-cis-pentadiene structure to fatty acid hydroperoxides. Linoleic acid, linolenic acid and arachidonic acid are the natural substrates of lipoxygenases (Su and Oliw 1998; Goldsmith et al. 2002).

Lipoxygenase catalyzed oxidative coupling reactions are utilized extensively in bread making. The addition of lipoxygenase-rich soybean flour results in the production of fatty acid hydroperoxides, which bleach the pigments of wheat flours. Lipoxygenase action also improves the mixing tolerance and rheological properties of the dough. (Frazier et al. 1973; Faubion and Hoseney 1981; Boussard et al. 2012. Furthermore, lipoxygenases have been used for bleaching dairy products such as cheese, milk, butter oil, cream, and whey (de Roos et al., 2006). Alcohols and aldehydes have been

\footnotetext{
* Correspondence: leo.degraaff@wur.nl

† Contributed equally

${ }^{2}$ Wageningen University, Laboratory of Systems and Synthetic Biology, Fungal Systems Biology, Dreijenplein 10, 6703 HB Wageningen, The Netherlands

Full list of author information is available at the end of the article
}

produced industrially from the fatty acid hydroperoxides that are formed in the lipoxygenase-catalyzed reactions. These compounds are used for flavouring foods (Whitehead et al. 1995).

Lipoxygenases have been detected in plants Feussner and Wasternack (2002); Baysal and Demirdöven 2007), mammals (Hammarberg et al. 1993), and in eukaryotic ( $\mathrm{Su}$ and Oliw 1998) and prokaryotic microorganisms (Koeduka et al. 2007; Vance et al. 2004). However, the recombinant production of secreted, stable lipoxygenases at high levels has only been achieved by the expression of the lipoxygenase gene of the fungus Gaeumannomyces graminis in Pichia pastoris (Cristea et al. 2005).

Many different assays for lipoxygenases have been developed (Axelrod et al. 1981; Williams et al. 1986; Suda et al. 1995; Villafuerte Romero and Barrett 1997; Anthon and Barrett 2001). The majority of these assays are based on detecting the fatty acid hydroperoxides formed, either indirectly by colorimetry or directly by UV-spectroscopy. However, for screening micoorganisms for industrially interesting enzymatic activities, plate assays are in most cases the method of choice, since this allows high-thoughput screening for the colonies expressing active enzyme. To our knowledge no 
agar plate assays have been developed for screening microorganisms for the production of secreted lipoxygenases. In this paper we present methods for the detection of lipoxygenase production in microorganisms. The test organisms include Trichoderma reesei, $P$. pastoris and Aspergillus nidulans expressing the G. graminis lipoxygenase gene, as well as the native lipoxygenase producer G. graminis triciti.

\section{Materials and methods}

\section{Cloning the G. graminis lipoxygenase gene}

The gene encoding the G. graminis lipoxygenase AAK81882.1 was codon-optimized and synthesized by GenScript custom gene synthesis service (GenScript Corporation, Piscataway, USA) for expression in P. pastoris. To facilitate cloning, EcoRI and KpnI restriction sites were added at the 5' and 3' ends of the fragment, respectively. The DNA fragment of the gene synthesized was ligated into the EcoRI and $K p n I$ sites of the vector pPICZ $\alpha$ A (Invitrogen) bringing the expression under the control of the methanol inducible AOX1 promoter. The native signal sequences were replaced with the prepro sequence of the Saccharomyces cerevisiae $\alpha$-factor secretion signal for secretion of the recombinant protein. P. pastoris wild-type strain X-33 (Invitrogen) was transformed by electroporation with the lipoxygenase expression vector that had been linearised with PmeI to target the integration into the AOX1 locus. The transformants were plated on YPDS plates containing $100 \mu \mathrm{l}$ $\mathrm{ml}^{-1}$ Zeocin (Invitrogen) and cultivated at $30 \mathrm{C}$. Single crossover recombination at the AOX1 locus was verified by PCR using $5^{\prime}$ and 3 ' AOX1 primers.

For expression in Trichoderma the G. graminis lipoxygenase encoding gene AAK81882.1 was codon-optimized and synthesized by GeneArt (Regensburg, Germany). To facilitate cloning, SacII and BamHI restriction sites were added at the 5 ' and 3 ' ends of the fragment, respectively. The DNA fragment of the synthesized gene was ligated into the SacII and BamHI sites of the expression vector pAB100 containing the strong $c b h I$-promoter of $T$. reesei. The native signal sequence of the recombinant lipoxygenase was used for secretion. T. reesei strain RH32578 was transformed as described (Penttilä et al. 1987) and transformants were screened for growth on plates with acetamide as sole nitrogen source. Resulting transformants were analyzed by PCR for integration of the lipoxygenase gene into the genome.

The gene encoding the G. graminis lipoxygenase AAK81882.1 was codon-optimized for expression in Aspergillus niger and synthesized by DNA 2.0 (Menlo Park, USA). For expression the promoter and secretion signal of the $x \ln D$ gene, from Aspergillus niger [GI 74626559] (Van Peij et al. 1997), replaced the native secretion signal of G. graminis. With help of the XbaI and $B a m H I$ restriction sites the synthesized gene was incorperated into a pUC19 vector and was used to transform the pyrA strain A. nidulans WG505. The transformants were plated on MMS plates (Kusters et al. 1991) for 4 days at 37 C. Positive transformants were analyzed by PCR for verification of integration of the lipoxygenase gene into the genome.

\section{Lipoxygenase plate assay methods}

A $25 \mathrm{mM}$ linoleic acid solution containing $14 \mathrm{mg} \mathrm{ml}^{-1}$ Tween 20 was used in the $\beta$-carotene bleaching assay and indamine dye formation assay was prepared as described previously (Anthon and Barrett 2001). All incubations were carried out in the dark at room temperature.

\section{$\beta$-carotene bleaching}

The half-saturated solution of $\beta$-carotene in acetone used in the assay was prepared as follows. Five $\mathrm{mg}$ of $\beta$ carotene was dissolved in $5 \mathrm{ml}$ of acetone. The suspension was mixed thoroughly and centrifuged for $10 \mathrm{~min}$ at $25000 \mathrm{~g}$. The supernatant was diluted with the same volume of acetone to give $50 \%$ saturation with respect to $\beta$-carotene.

The linoleic acid agarose solution contained $2.3 \mathrm{mM}$ linoleic acid, $1 \%\left(\mathrm{w} \mathrm{v}^{-1}\right)$ low melting point agarose (Seaplaque) and $50 \mathrm{mM}$ potassium phosphate buffer $(\mathrm{pH}$ 7.0). The linoleic acid agarose solution was mixed at a ratio of 39:5 $\left(\mathrm{w} \mathrm{v}^{-1}\right)$ with half-saturated solution of $\beta$ carotene in acetone and applied as an overlay. This method is based on a previously described lipoxygenase assay of liquid samples (Villafuerte Romero and Barrett 1997).

\section{Indamine dye formation}

The indamine dye formation assay is based on the chemical reaction described by Ngo and Lenhoff (1980) A 10 mM DMAB [3-(dimethylamine) benzoic acid] stock solution buffered with $200 \mathrm{mM}$ disodium phosphate $\mathrm{pH}$ 6.0; the $10 \mathrm{mM}$ MBTH (3-Methyl-2-benzothiazolinone) stock solution and the $0.1 \mathrm{mg} \mathrm{ml}^{-1}$ hematin stock solution buffered with $5 \mathrm{mM} \mathrm{NaOH}$ were prepared as described previously (Anthon and Barrett, 2001). An overlay of agarose with linoleic acid and the coloring reagents contained $2.3 \mathrm{mM}$ linoleic acid, $1 \%\left(\mathrm{w} \mathrm{v}^{-1}\right)$ agarose, $50 \mathrm{mM}$ K-phosphate buffer ( $\mathrm{pH} 7.0), 4.6 \mathrm{mM}$ DMAB, $0.1 \mathrm{mM} \mathrm{MBTH}$, and $1 \mu \mathrm{g} \mathrm{l} \mathrm{l}^{-1}$ hematin.

\section{Potassium iodide (KI) - starch method}

The potassium iodide assay described by Williams et al. (1986) was modified for detecting lipoxygenase activity of agar cultures. A linoleic acid solution was prepared by mixing linoleic acid $(700 \mu \mathrm{l})$ and Tween $20(700 \mu \mathrm{l})$ with $5 \mathrm{ml}$ water. The resulting emulsion was clarified by adding $1 \mathrm{ml} 1 \mathrm{M} \mathrm{NaOH}$ and diluted to a final volume of $25 \mathrm{ml}$. For detecting lipoxygenase activity $100 \mu \mathrm{l}$ of 
the linoleic acid solution was added into wells on agar containing $40 \mathrm{~g} \mathrm{l}^{-1}$ starch. After incubation, $100 \mu \mathrm{l}$ of saturated potassium iodide solution and $75 \mu \mathrm{l}$ of $75 \%(\mathrm{v}$ $\mathrm{v}^{-1}$ ) acetic acid were added into the wells and mixed.

\section{Comparison of the sensitivities of the assays}

An ammonium sulfate suspension of type $\mathrm{V}$ soybean lipoxygenase (sLOX-1) (Sigma) was diluted with $50 \mathrm{mM}$ potassium phosphate buffer at $\mathrm{pH}$ 7.0. $25 \mu \mathrm{l}$ of the lipoxygenase solution was applied into wells in LB-agar in amounts ranging from $8 \mathrm{ng}$ to $1 \mu \mathrm{g}$ lipoxygenase per well. For the the KI-starch method starch was added to the LB-agar as described above. For comparison of the sensitivities, the plates were incubated at room temperature for $2 \mathrm{~h}$ and examined visually.

\section{Cultivation of the microorganisms on agar plates for detection of lipoxygenase activity}

The $P$. pastoris transformants were grown at $30^{\circ} \mathrm{C}$ for 3 days on BMMY (Buffered Methanol Complex Medium, Invitrogen) agar before analysis. The inducer methanol was added daily to the lid of the inverted plate to compensate for loss due to evaporation. The T. reesei transformants were grown on potato dextrose agar at 28-30 C. For analysis using the KI-starch method the plates were supplemented with starch as described above. The A. nidulans transformants were grown on $50 \mathrm{mM} \mathrm{D}$ xylose minimal medium plates (Pontecorvo et al. 1953) containing $1.2 \%$ agar while potato dextrose was omitted to prevent carbon catabolite repression. G. graminis var. tritici CBS 905.73 was grown on potato dextrose agar at $25^{\circ} \mathrm{C}$. For analysis by the KI-starch method the medium was supplemented with starch as described above. For the indamine dye formation assay the coloring reagents were applied as an agarose overlay.

\section{Effect of the linoleic acid oxidation products on the growth of $E$. coli}

To study the inhibitory effects of the reaction products of lipoxygenase catalyzed oxidation, linoleic acid was dispersed by mechanical homogenization into LB-agar at a concentration of $0.4 \%\left(\mathrm{w} \mathrm{v}^{-1}\right) .4 \mu \mathrm{l}$ of a solution containing $0.5,1.8$ and $7.2 \mu \mathrm{g}$ of soybean lipoxygenase (Sigma L-7395) in 50\% ( $\left.\mathrm{w} \mathrm{v}^{-1}\right)$ glycerol, $100 \mathrm{mM} \mathrm{Na-}$ phosphate buffer, $\mathrm{pH} 7.0$ was applied into wells present in the agar and the plates were incubated for $30 \mathrm{~min}$ at room temperature. E. coli (XL1-blue) suspensions were spread on the plates after the incubation and the cells were grown overnight.

Detection of lipoxygenase activity by the indamine dye formation method in the presence of $E$. coli cells

Wells were punched into LB-agar plates and were inoculated with $400 \mu \mathrm{l}$ of $E$. coli (XL1-blue) suspension in LB medium and the cells were cultivated over-night at $37^{\circ} \mathrm{C}$ as a lawn on the plates sLOX-1 (Sigma) was diluted with $50 \mathrm{mM}$ potassium phosphate buffer, $\mathrm{pH}$ 7.0 , and $25 \mu \mathrm{l}$ of the lipoxygenase solution was applied into the wells in the agar at final amounts ranging from $8 \mathrm{ng}$ to1 $\mu \mathrm{g}$. After the enzyme solutions had absorbed, the indamine dye formation agarose was applied either as a single layer or sequentially as two layers of equal volume. In the latter case the first layer contained 4.6 $\mathrm{mM}$ linoleic acid and $100 \mathrm{mM}$ K-phosphate buffer $\mathrm{pH}$ 7.0 and the second layer contained 9.2 mM DMAB, 0.2 $\mathrm{mM} \mathrm{MBTH}$ and $2 \mu \mathrm{g}$ hematin. After the application of the first layer the plates were incubated overnight at room temperature and the second layer was applied. Experiments both with and without $0.5 \mathrm{mM}$ EDTA in the overlays were carried out.

\section{Results}

\section{Comparison of the assays for detection of soybean lipoxygenase}

Lipoxygenase catalyzed formation of hydroperoxides resulted in a violet-blue color with the indamine dye formation method, a brown color with the potassium iodine-starch method and bleached halos in the yelloworange agarose background with the $\beta$-carotene bleaching method.

To compare the three methods soybean lipoxygenase was applied on the agar plate and analyzed. As shown in Figure 1, the soybean lipoxygenase activity on linoleic acid was detectable by all three colorimetric methods. The sensitivities of the indamine dye formation and KI starch methods were of the same order, the detection limits being between 63 and 130 ng soybean lipoxygenase. The $\beta$-carotene bleaching method appeared to be the least sensitive of the three methods tested, since the detection limit was between $0.25 \mu \mathrm{g}$ and $0.5 \mu \mathrm{g}$ of soybean lipoxygenase. Therefore, $\beta$-carotene bleaching was not used for the assays for lipoxygenase activity in further experiments.

\section{Detection of lipoxygenase production by microbial transformants}

P. pastoris, T. reesei and $A$. nidulans transformants with and without the lipoxygenase gene of G. graminis were grown on agar plates and were induced as described in Materials and Methods. The transformants were analyzed for lipoxygenase activity using the KI-starch and indamine color formation methods. As shown in Figure 2, both $P$. pastoris transformants with the lipoxygenase gene gave clear positive signals with both methods. For the assay using the KI-starch method it proved to be necessary to grow the Pichia transformants on plates composed of a layer without starch on top and a layer with it on the bottom. Wells were punched in the upper 


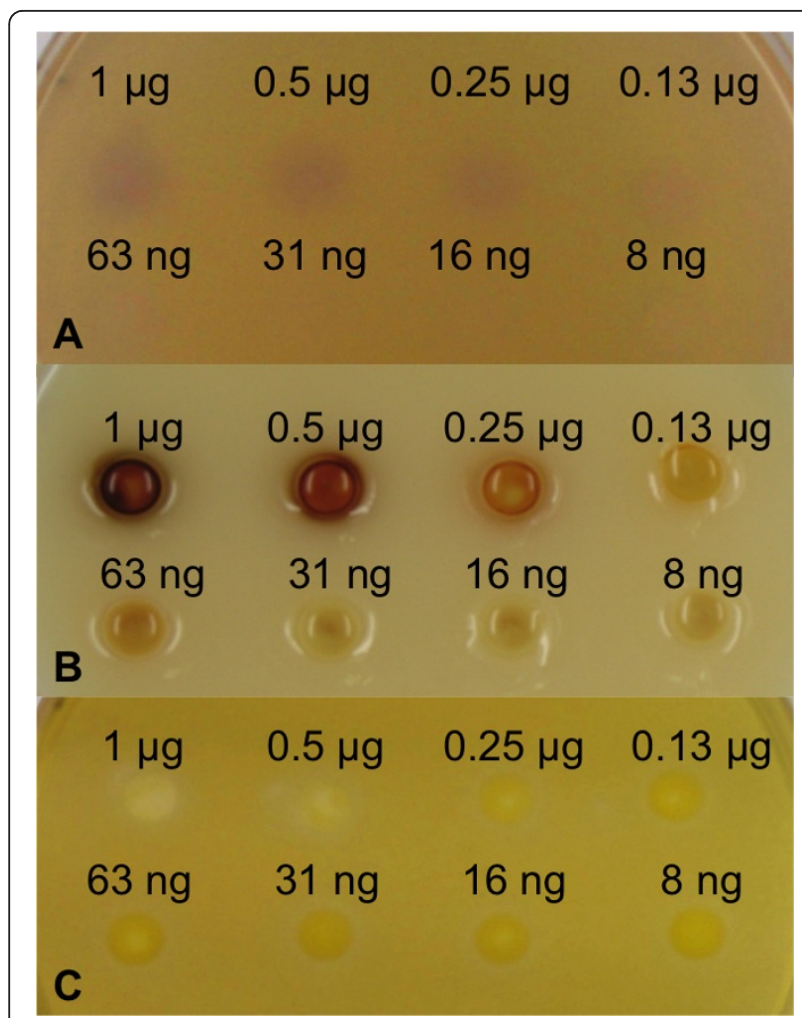

Figure 1 Comparison of the sensitivities of $(A)$ indamine dye formation, (B) Kl-starch, and (C) $\beta$-carotene bleaching methods. Different concentrations of SLOX-1 were applied on the agar plates. The plates were incubated for $2 \mathrm{~h}$ at room temperature.

layer in the vicinity of the colonies and the reagents added. Possibly the starch used contained traces of free sugars that caused carbon catabolite repression of expression.

Figure 3 shows a clear brown colour around the mycelium of $T$. reesei while this was not found for the wild type showing the plate assay can also be used for this organism. For the plate assays using $A$. nidulans

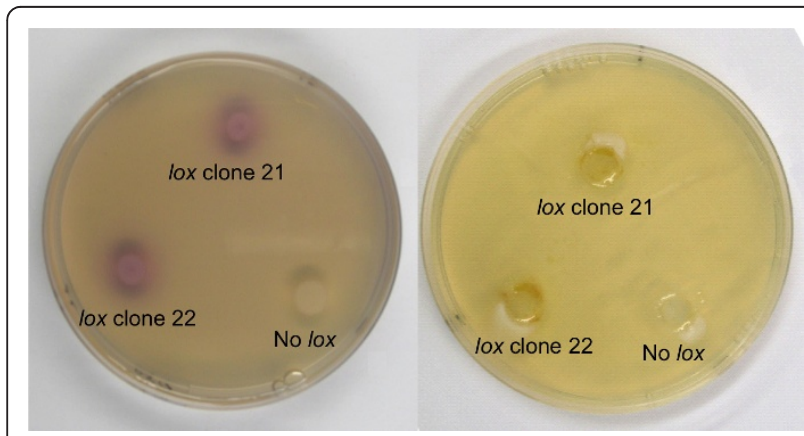

Figure 2 Lipoxygenase detection of $P$. pastoris transformants expressing the lipoxygenase of $G$. graminis (A) analyzed by the indamine dye formation method and (B) analyzed by the KIstarch method.

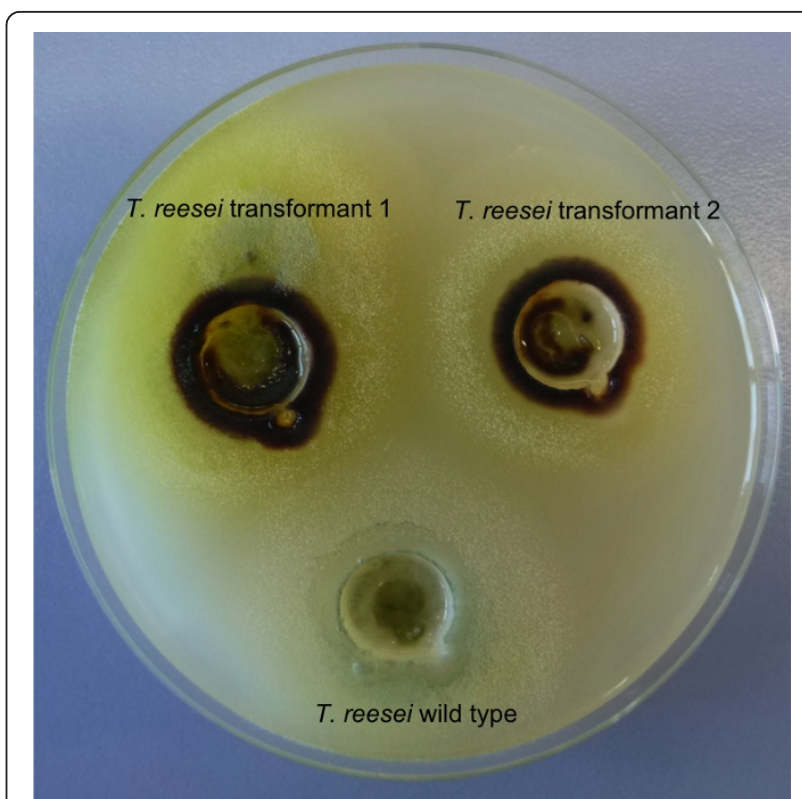

Figure 3 Detection of G. graminis lipoxygenase activity on $T$. reesei transformants grown on plate. Positive transformants show a brown color around the mycelium.

potato dextrose was replaced by $\mathrm{D}$-xylose to prevent inhibition of lipoxygenase by carbon catabolite respression. In these transformants the D-xylose inducible $x \ln D$ promoter (Van Peij et al. 1997) was used for the expression of the lipoxygenase. The results of the assay are shown in Figure 4, positive transformants for

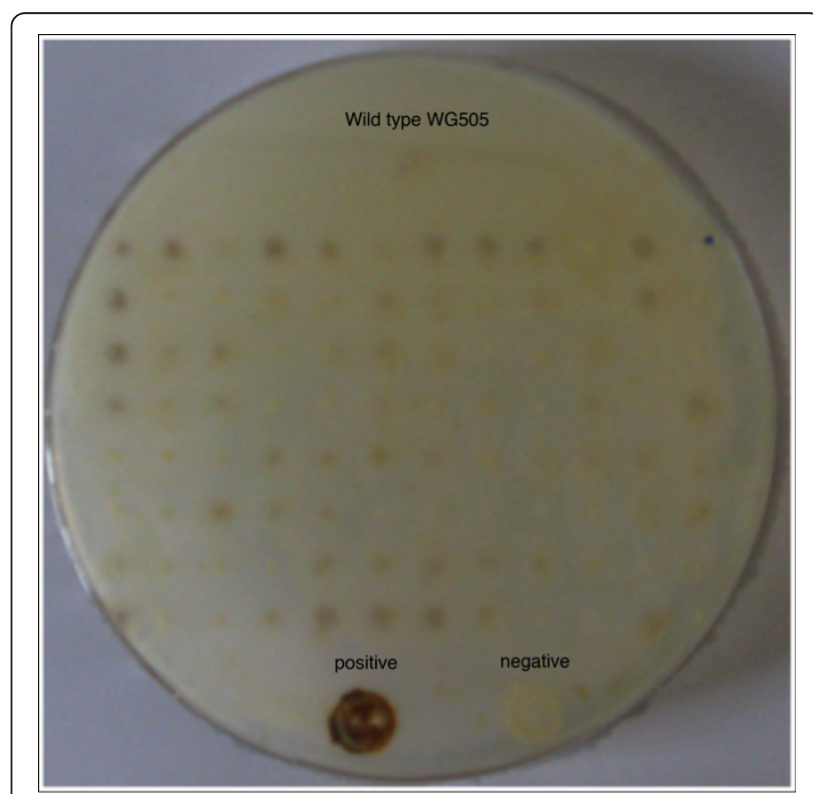

Figure 4 Detection of $G$. graminis lipoxygenase activity in $A$. nidulans transformants using the $\mathrm{KI}$-starch assay. Positive transformants are visualized as brown dots in the plate. 
lipoxygenase activity are visible as a brown colony while wild type did not stain. The indamine color assay was not successful for $A$. nidulans, which is probably due to the low expression level of enzyme in this organism.

\section{Effects of lipoxygenase reaction products on growth of $E$. coli and detection of lipoxygenase activity in the presence of $E$. coli cells}

To study the effect of the oxidation products of linoleic acid on the growth of $E$. coli, soybean lipoxygenase was applied on linoleic acid LB-agar. After incubation, E. coli cells were grown overnight as a lawn on the plates. As shown in Figure 5 clear growth inhibiting zones could be detected on the plates around the soybean lipoxygenase (between $0.11 \mu \mathrm{g}$ and $7.2 \mu \mathrm{g}$ of the enzyme preparate) application points.

The possibility that $E$. coli cells interfere with the lipoxygenas activity was investigated by applying soybean lipoxygenase on a lawn of growing cells. When all indamine dye formation reagents were added as a single layer only between $0.5 \mu \mathrm{g}$ and $1 \mu \mathrm{g}$ soybean lipoxygenase could be detected after $5 \mathrm{~h}$ of incubation. When the plates were incubated overnight the blue indamine color had disappeared. However, when the linoleic acid agarose was added first, followed by an overnight incubation and addition of the coloring reagent agarose, the violetblue color was clearly visible at between $63 \mathrm{ng}$ and 130 ng of soybean lipoxygenase (Figure 6). In both cases the

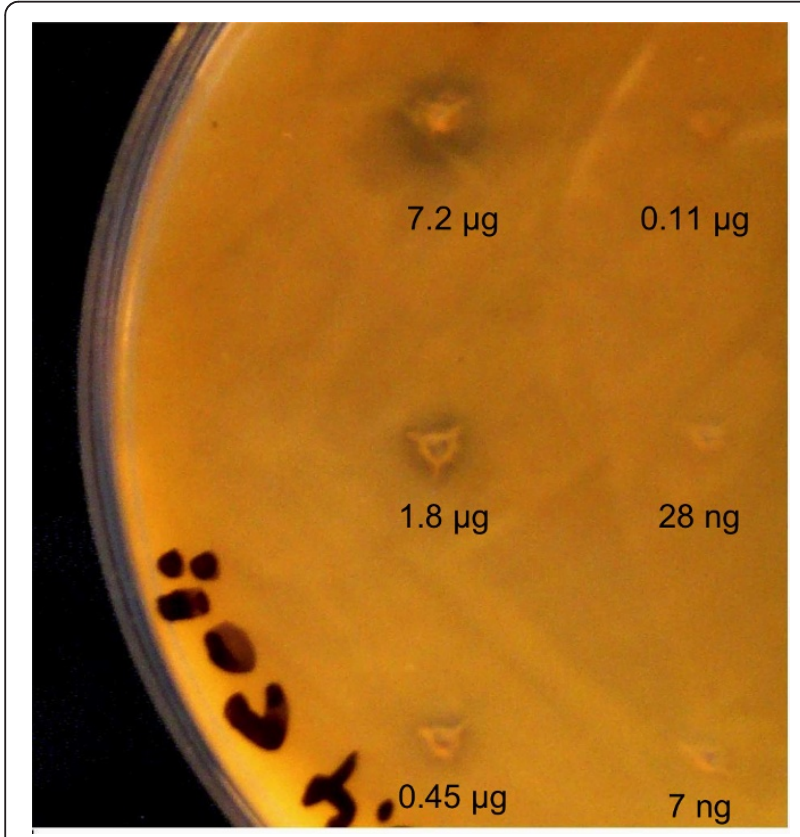

Figure 5 Overnight growth $E$. coli on linoleic acid agar supplemented with sLOX-1. The plates were incubated for $30 \mathrm{~min}$ at room temperature in the presence of different amounts of the lipoxygenase and inoculated with the cell suspension.

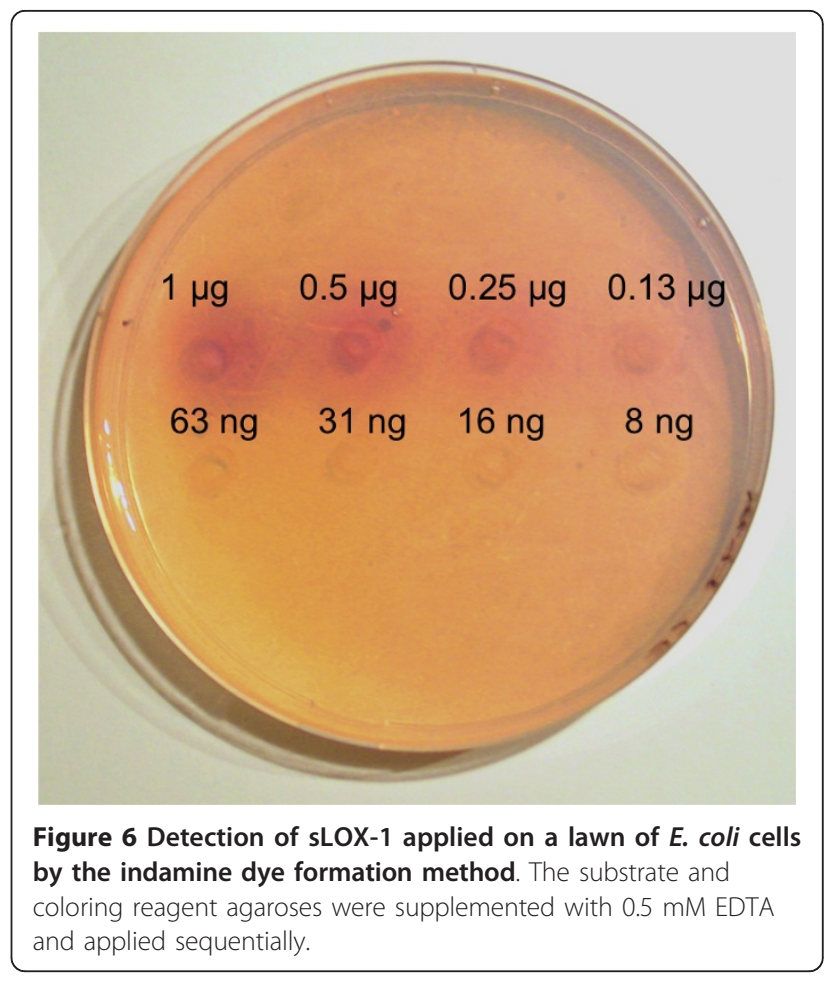

addition of 0.5 M EDTA intensified the signal (data not shown).

\section{Discussion}

The methods used in the current work for identification of lipoxygenase producing transformants on agar plates are all based on the detection of the linoleic acid hydroperoxides formed in the lipoxygenase catalyzed reaction. In the indamine dye formation method 3-methyl-2-benzothiazolinone (MBTH) is coupled oxidatively with 3(dimethylamino) benzoic acid (DMAB) in a hematin catalyzed reaction, which results in the generation of the indamine dye (Anthon and Barrett 2001). In the potassium iodide starch method the fatty acid hydroperoxides formed oxidize iodide to iodine, which in turn reacts with starch (Williams et al. 1986). $\beta$-Carotene can be used for lipoxygenase detection, since it is bleached by the fatty acid hydroperoxides (Villafuerte Romero and Barrett 1997).

The indamine dye formation and KI-starch methods appeared to be more sensitive than the $\beta$-carotene bleaching method for detection of lipoxygenase activity. The poor sensitivity of the $\beta$-carotene bleaching method has also been established in a previous report in which different liquid assays for detecting lipoxygenase activity from vegetable extracts were compared (Villafuerte Romero and Barrett 1997).

The reaction products of lipoxygenase-catalyzed oxidation of linoleic acid appeared to be toxic for $E$. coli 
cells. It has also been shown previously that fatty acid hydroperoxides and their degradation products (oxylipins) impair the growth of many microbial plant pathogens (Prost et al., 2005). If linoleic acid is present in the growth medium from the onset of the cultivation, the lipoxygenase producers may thus not be able to survive. Linoleic acid can also be spontaneously degraded via auto-oxidation during longer incubations (Seo et al. 1999). For these reasons, we chose to omit linoleic acid from the agar medium. Lipoxygenase positive $T$. reese $i$ and $P$. pastoris transformants expressing the G. graminis lipoxygenase gene could be clearly identified by both KI-starch and indamine dye formation methods. These methods could also most likely be used for other microbial production hosts. For the $A$. nidulans transformants only the KI-starch assay was successful. The indamine dye formation method did not show clear results for detection of lipoxygenase (data not shown).

A potential problem in screening $E$. coli-hosted metagenomic libraries is that the cells are able to use the lipoxygenase substrate, linoleic acid, for growth. This problem can, however, most probably be overcome by disrupting genes encoding fatty acid transport and/or $\beta$ oxidation present in the fad regulon (DiRusso and Nyström, 1998). However, as stated above, adding linoleic acid to the medium may not be feasible, because positive transformants can produce toxic substances via the lipoxygenase catalyzed oxidation of the substrate.

Preferably tens of thousands of metagenomic library colonies would have to be screened to find lipoxygenase activity. Furthermore, it is typical for metagenomic expression libraries that the activities are low and may be detectable only after prolonged cultivations (Uchiyama and Miyazaki 2009). The use of the KI-starch method is problematic for the detection of lipoxygenase producing transformants of metagenomic libraries, since the color reaction takes place under very acidic conditions. Iodine is also a well-known microbicide (Vasudevan and Tandon 2010). We chose therefore the indamine dye formation method for investigation whether lipoxygenase activity can be detected in the presence of $E$. coli cells. If linoleic acid and the coloring reagents were applied as one layer on the E. coli culture supplemented with soybean lipoxygenase, the violet-blue color was for unknown reasons only transiently visible. However, when the substrate agarose was applied first, followed by incubation and application of the coloring agarose, the soybean lipoxygenase catalyzed reaction was clearly detectable. EDTA intensified the signal, possibly because it chelates metal ions, which can catalyze hydroperoxide degradation.

It can be concluded that the KI-starch and the indamine dye formation method can both be used for detection of lipoxygenase producing transformants of
P. pastoris and T. reesei, and possibly also of other microbial hosts. Furthermore, the indamine dye formation method holds promise for identification of lipoxygenase positive transformants of $E$. coli-hosted metagenomic libraries. However, at the present the detection of lipoxygenase production by natural isolates growing on agar remains a challenge.

\section{Acknowledgements}

The authors gratefully acknowledge the financial support provided by the European Research Project (Novel enzyme tools for production of functional oleochemicals from unsaturated lipids (ERA-NOEL), ERA-IB/BIO/0001/2008)

\section{Author details}

${ }^{1}$ VTT Biotechnology, P.O. Box 1500, FIN-02044 VIT, Finland ${ }^{2}$ Wageningen University, Laboratory of Systems and Synthetic Biology, Fungal Systems Biology, Dreijenplein 10,6703 HB Wageningen, The Netherlands ${ }^{3} \mathrm{AB}$ Enzymes GmbH, Feldbergstrasse 78, D-64293 Darmstadt, Germany

\section{Competing interests}

The authors declare that they have no competing interests.

Received: 15 February 2012 Accepted: 26 March 2012

Published: 26 March 2012

\section{References}

Anthon GE, Barrett DM (2001) Colorimetric method for the determination of lipoxygenase activity. J Agric Food Chem 49:32-37. doi:10.1021/jf000871s.

Axelrod B, Cheesbrough TM, Laakso S (1981) Lipoxygenase from soybeans. Methods Enzymol 71:441-451

Baysal T, Demirdöven A (2007) Lipoxygenase in fruits and vegetables: A review. Enzyme Microb Technol 40:491-496. doi:10.1016/j.enzmictec.2006.11.025

Boussard A, Cordella CBY, Rakotozafy L, Moulin G, Buche F, Potus J, Nicolas J (2012) Use of chemometric tools to estimate the effect of the addition of yeast, glucose-oxidase, soybean or hors bean flours to wheat flour on biochemical bread dough characteristics. Chemom and Intel Lab Systems (in press). (article in press)

Cristea M, Engström Å, Su C, Hörnsten L, Oliw EH (2005) Expression of manganese lipoxygenase in Pichia pastoris and site-directed mutagenesis of putative metal ligands. Arch Biochem Biophys 434:201-211. doi:10.1016/j. abb.2004.10.026

DiRusso CC, Nyström T (1998) The fats of Escherichia coli during infancy and old age: regulation by global regulators, alarmones and lipid intermediates. Mol Microbiol 27:1-8. doi:10.1046/j.1365-2958.1998.00645.x

Faubion JM, Hoseney RC (1981) Lipoxygenase: Its biochemistry and role in breadmaking. Cereal Chem 58:175-180

Feussner I, Wasternack C (2002) The lipoxygenase pathway. Annu Rev Plant Biol 53:275-297. doi:10.1146/annurev.arplant.53.100301.135248.

Frazier PJ, Leigh-Dugmore FA, Daniels NWR, Russell Eggitt PW, Coppock JBM (1973) The effect of lipoxygenase action on the mechanical development of wheat flour doughs. J Sci Fd Agric 24:421-436. doi:10.1002/jsfa.2740240411.

Goldsmith CR, Jonas RT, Stack TDP (2002) C-H bond activation by a ferric methoxide complex: modeling the rate-determining step in the mechanism of lipoxygenase. J Am Chem Soc 124:83-96. doi:10.1021/ja016451g.

Hammarberg T, ZhangY-Y LB, Rådmark O, Samuelsson B (1993) Iron content of human 5-lipoxygenase, effects of mutations regarding conserved histidine residues. J Biol Chem 268:2535-41

Seo H-S, Endo Y, Fujimoto K (1999) Kinetics for the autoxidation of conjugated linoleic acid. Biosci Biotechnol Biochem 63:2009-2010. doi:10.1271/bbb.63.2009.

Koeduka T, Kajiwara T, Matsui K (2007) Cloning of lipoxygenase genes from a cyanobacterium, Nostoc punctiforme, and its expression in Escherichia coli. Curr Microbiol 54:315-319. doi:10.1007/s00284-006-0512-9.

Kusters MA, Harmsen JAM, Kester HCM, Visser J (1991) Structure of the Aspergillus niger pelA gene and its expression in Aspergillus niger and Aspergillus nidulans. Curr Genet 20:293-299. doi:10.1007/BF00318518.

Ngo TT, Lenhoff HM (1980) A sensitive and versatile chromogenic assay for peroxidase and peroxidase-coupled reactions. Anal Biochem 105:389-397. doi:10.1016/0003-2697(80)90475-3. 
Penttilä M, Nevalainen H, Rättö M, Salminen E, Knowles J (1987) A versatile transformation system for the cellulolytic filamentous fungus Trichoderma reesei. Gene 61:155-164. doi:10.1016/0378-1119(87)90110-7.

Pontecorvo G, Roper JA, Hemmons LM, Macdonald KD, Bufton AW (1953) The genetics of Aspergillus nidulans. Adv Genet 5:141-238

Prost I, Dhondt S, Rothe G, Vicente J, Rodriguez MJ, Kift N, Carbonne F, Griffiths G, Esquerré-Tugayé MT, Rosahl S, Castresana C, Hamberg M (2005) Fournier Evaluation of the antimicrobial activities of plant oxylipins supports their involvement in defense against pathogens. Plant Physiol 139:1902-1913. doi:10.1104/pp.105.066274.

Van Peij NNME, Brinkmann J, Vrsanská M, Visser J, de Graaff LH (1997) betaxylosidase activity, encoded by $\mathrm{xlnD}$, is essential for complete hydrolysis of xylan by Aspergillus niger but not for induction of the xylanolytic enzyme spectrum. Eur J Biochemistry 245:164-173. doi:10.1111/j.14321033.1997.00164.x.

de Roos AL, van Dijk AA, Folkertsma B (2006) Bleaching of dairy products. US Patent US 2006/0127533 A1

Su C, Oliw EH (1998) Manganese lipoxygenase. Purification and characterization Biol Chem 273:13072-13079

Suda I, Hajika M, Nishiba Y, Furuta S, Igita K (1995) Simple and rapid method for the selective detection of individual lipoxygenase isozymes in soybean seeds. J Agric Food Chem 43:742-747. doi:10.1021/jf00051a034.

Uchiyama T, Miyazaki K (2009) Functional metagenomics for enzyme discovery: challenges to efficient screening. Curr Opin Biotechnol 20:616-622. doi:10.1016/j.copbio.2009.09.010.

Vance RE, Hong S, Gronert K, Serhan CN, Mekalanos JJ (2004) The opportunistic pathogen Pseudomonas aeruginosa carries a secretable arachidonate 15lipoxygenase. Proc Natl Acad Sci USA 101:2135-2139. doi:10.1073/ pnas.0307308101.

Vasudevan P, Tandon M (2010) Antimicrobial properties of iodine based products. J Sci Ind Res 69:376-383

Whitehead IM, Muller BL, Dean C (1995) Industrial use of soybean lipoxygenase for the production of natural green note flavour compounds. Cereal Foods World 40:193-197

Villafuerte Romero M, Barrett DM (1997) Rapid methods for lipoxygenase assay in sweet corn. J Food Sci 62:696-700. doi:10.1111/j.1365-2621.1997.tb15438.x.

Williams DC, Lim MH, Chen AO, Pangborn RM, Whitaker JR (1986) Blanching of vegetables for freezing - which indicator enzyme to choose. Food Technol 40:130-140

doi:10.1186/2191-0855-2-17

Cite this article as: Nyyssölä et al:: Methods for identifying lipoxygenase producing microorganisms on agar plates. AMB Express 2012 2:17

\section{Submit your manuscript to a SpringerOpen ${ }^{\circ}$ journal and benefit from:}

- Convenient online submission

- Rigorous peer review

- Immediate publication on acceptance

- Open access: articles freely available online

- High visibility within the field

- Retaining the copyright to your article

Submit your next manuscript at $>$ springeropen.com 